\title{
Pequena história do brinquedo em tempos sombrios
}

Small History of the Toy in Dark Times

\section{José Antônio Orlando*}

Universidade Federal de Minas Gerais (UFMG) | Belo Horizonte, Brasil semioticas@hotmail.com

Resumo: Jogos, brinquedos e brincadeiras formam uma parte importante de nossas identidades individuais e coletivas, assim como sempre fizeram parte de todas as culturas em todas as épocas. Mas o que as maneiras de brincar dizem sobre uma sociedade? No último século, Walter Benjamin, vivendo na Alemanha em tempos sombrios que testemunhavam o avanço rumo à tomada do poder e à destruição pelo nazismo, foi um dos pensadores que deixaram escritos reveladores sobre a prática de jogos e sobre as formas alegóricas de brincar. As reflexões de Benjamin e de outros pensadores, entre eles Hannah Arendt, fornecem o pano de fundo para estudos contemporâneos sobre a historiografia e a ideologia das formas de brincar, com destaque para o acervo reunido por André Postert em "Kinderspiel, Glücksspiel, Kriegsspiel: Große Geschichte in kleinen Dingen 1900-1945" (Jogo infantil, jogo de sorte, jogo de guerra: Grande História em pequenas coisas 1900-1945).

Palavras-chave: Brinquedos. Nazismo. André Postert.

Abstract: Games, toys and games form an important part of our individual and collective identities, just as they have always been part of all cultures at all times. But what do ways of playing say about a society? In the last century, Walter Benjamin, living in Germany in dark times that witnessed the advance towards the seizure of power and destruction by Nazism, was one of the thinkers who left revealing writings on the practice of games and on allegorical ways of playing. The reflections of Benjamin and other thinkers, including Hannah Arendt, provide the backdrop for contemporary studies on the historiography and ideology of ways of playing, with emphasis on the collection put together by André Postert in "Kinderspiel, Glücksspiel, Kriegsspiel: Große Geschichte in kleinen Dingen 1900-1945" (Children's game, game of chance, war game: Great History in small things 1900-1945).

Keywords: Toys. Nazism. André Postert.

No senso comum está, muitas vezes, a ideia de que tanto jogos, brinquedos e brincadeiras, como as etiquetas do antigo comportamento em geral eram muito melhores que hoje em dia, seja esta ideia um modo melancólico de utopia nostálgica

* Doutorando em Letras: Estudos Literários no Programa de Pós-Graduação em Estudos Literários da Universidade Federal de Minas Gerais. 
ou mesmo um argumento para criticar e contrapor, em nossa atualidade, a onipresença cotidiana de objetos eletrônicos e virtuais, videogames e telemáticas de formatos e definições variadas, computadores, celulares e seus similares. A percepção do senso comum também confirma que jogos e brinquedos formam uma parte importante da nossa identidade na trajetória de nossas vidas individuais e coletivas, assim como sempre fizeram parte de todas as culturas em todas as épocas. Mas o que as maneiras de brincar dizem sobre uma sociedade?

A questão foi objeto de investigação filosófica, sociológica e histórica por pensadores e pesquisadores das mais diversas áreas e nacionalidades, de Sigmund Freud e Ludwig Wittgenstein a Johan Huizinga, de Jean Piaget e Roger Caillois a Umberto Eco, de Maria Montessori e Joffre Dumazedier a Ellen Key, de Lev Vygotsky e Melanie Klein a Roland Barthes, de Walter Benjamin a Paulo Freire e Tizuko Kishimoto, entre vários outros. Na Antiguidade Clássica, Aristóteles já destacava o valor do jogo por sua autossuficiência, nos livros de sua "Arte Retórica", e interrogava sobre sua causa final em variáveis como luta e disputa, derrota e vitória, para concluir que, em toda circunstância, são as formas do prazer pelo próprio jogo o que procuram aqueles que jogam. ${ }^{1}$ Sobre as reflexões pioneiras de Aristóteles talvez seja também importante lembrar que, em grego, há uma revelação etimológica sobre as relações que se estabelecem entre infância, jogos e brincadeiras: todos os vocábulos referentes a atividades lúdicas estão ligados à palavra criança ("pais", "paidí", "paidós") e o verbo "paizeim", que se traduz por "brincar", significa literalmente "fazer de criança" e também pode ser traduzido por "hora de brincar" ou "agir como criança". ${ }^{2}$

No último século, Walter Benjamin, vivendo na Alemanha em tempos sombrios que testemunhavam o avanço rumo ao poder e à destruição pelo nazismo, deixou pesquisas e escritos reveladores sobre a prática de jogos como repetição e sobre as formas alegóricas de brincar. No ensaio "Brinquedos e jogos", publicado em 1928 com

${ }^{1}$ Em Brincar na educação infantil, Gisela Wajskop ressalta que, desde a Antiguidade Clássica, filósofos como Platão e Aristóteles já pensavam o brinquedo na educação associando a ideia de estudo ao prazer e considerando a brincadeira como um instrumento importante para o ensino. "A brincadeira é uma forma de comportamento social, que se destaca da atividade do trabalho e do ritmo cotidiano da vida, reconstruindo-os para compreendê-los segundo uma lógica própria, circunscrito e organizado no tempo e no espaço" (WAJSKOP, 2012, p. 35).

2 Michel Manson, em História do brinquedo e dos jogos, ao apontar as acepções dos termos brinquedo, brincadeira e jogo, em grego e latim, destaca que, em latim, a palavra "ludribrum", proveniente de "ludus" (jogo), não está ligada à infância e é sempre usada em sentido metafórico (MANSON, 2002, p. 30-32). 
o subtítulo "Observações marginais sobre uma obra monumental", ${ }^{3}$ e apresentado como estudo crítico sobre a publicação do livro de Karl Gröber Kinderspielzeug aus alter Zeit. Eine Geschichte des Spielzeugs (Brinquedos infantis de velhos tempos. Uma história do brinquedo), também de 1928, Benjamin ressalta a polissemia da palavra "jogos" na língua alemã e suas acepções como "lei da repetição" que podem referir-se tanto ao manuseio mais simples de objetos inanimados como aos aspectos de maior complexidade das convenções e cerimônias nas relações sociais e conclui: "A essência do brincar não é um 'fazer como se', mas um 'fazer sempre de novo', transformação da experiência mais comovente em hábito". ${ }^{4}$

No duplo sentido, em alemão, da palavra "spiele" e da prática de jogos, de brinquedos e de brincadeiras, ${ }^{5}$ Benjamin também alerta em outro ensaio sobre o mesmo assunto,

${ }^{3}$ Publicado em Reflexões sobre a criança, o brinquedo e a educação. Trad. Marcus Vinicius Mazzari. São Paulo: Duas Cidades; Editora 34, 2002. p. 95-102.

${ }^{4}$ No ensaio citado, o tradutor, em nota, esclarece a complexidade do termo "jogos" na acepção a que Benjamin se refere: "Spiele no original, que pode ser traduzido aqui tanto por 'jogos' como 'brincadeiras'; além disso, o verbo spielen, relacionado a esse substantivo, tem, entre outros significados, o de 'brincar', 'jogar', assim como o de 'representar' (no teatro, por exemplo). Benjamin parece aludir à polissemia dessa palavra quando fala do 'duplo sentido nos jogos alemães'”' (BENJAMIN, 2002, p. 100102).

5 Sobre a diferenciação na língua portuguesa para o sentido dos termos jogos, brinquedos e brincadeiras, há um esclarecimento didático e fundamental apresentado por Tizuko Morchida Kishimoto, pesquisadora da Faculdade de Educação da Universidade de São Paulo, em Jogo, brinquedo, brincadeira e a educação, que será adotado como referência neste artigo, uma vez que tais conceitos e as palavras que os identificam não são precisos nem na língua portuguesa nem em grande parte das demais. Segundo Kishimoto, o termo "brinquedo" deve ser entendido como objeto de brincar, como suporte para a importância do brincar na construção de conhecimentos de crianças na pré-escola ou nos estágios posteriores de desenvolvimento e de sociabilidade. O termo "brincadeira" deve corresponder à ação que a criança ou adolescente desempenha ao concretizar as regras do jogo, ao mergulhar na ação lúdica. O termo "jogo" deverá ser entendido tanto como um objeto, quanto como as regras que orientam uma disputa. Estes termos estão inseridos em um universo mais abrangente, a dimensão do lúdico. O brincar diz respeito à ação lúdica, seja brincadeira ou jogo, com ou sem o uso de brinquedos ou outros materiais ou objetos. Com base nas teses de Piaget, Montessori, Vygotsky e Freud sobre a educação infantil, Kishimoto alerta que um dos objetivos do brinquedo é dar à criança ou ao adolescente um substituto dos objetos reais, para que possam manipulá-los. Enquanto objeto, o brinquedo é sempre suporte da brincadeira. E a brincadeira é a ação com frequência 
"História social do brinquedo", também de 1928, que a fabricação de brinquedos como artefato de consumo é um acontecimento da modernidade que, na segunda metade do século 19, deixa o núcleo afetivo da produção familiar para se transformar em mercadoria reproduzida em escala industrial. ${ }^{6}$ Tal metamorfose altera de maneira muito significativa tanto as maneiras de brincar como as fantasias e percepções construídas na brincadeira, nas lutas e na destruição dos brinquedos, nos objetos e na imaginação que marcam a vida cotidiana estampada no singular e no plural das experiências:

O hábito entra na vida como brincadeira, e nele, mesmo em suas formas mais enrijecidas, sobrevive até o final um restinho da brincadeira. Formas petrificadas e irreconhecíveis de nossa primeira felicidade, de nosso primeiro terror, eis o que são os hábitos [...]. Mas quando um poeta moderno diz que para cada um existe uma imagem em cuja contemplação o mundo inteiro submerge, para quantas pessoas essa imagem não se levanta de uma velha caixa de brinquedos? ${ }^{7}$

O questionamento filosófico e nostálgico identificado por Walter Benjamin em 1928, motivado pelo livro de Karl Gröber e seu acervo de reproduções de 306 figuras, incluindo 12 páginas com lâminas coloridas, parece ter sido tomado literalmente como fio condutor por André Postert, historiador que desde 2014 atua como pesquisador associado ao Instituto Hannah Arendt na cidade alemã de Dresden. Postert investigou durante anos, em arquivos e bibliotecas da Alemanha e de outros países, os registros mais variados sobre os jogos infantis e as velhas caixas de brinquedos, com um levantamento mais minucioso sobre o período da primeira metade do século 20 . Os resultados das pesquisas foram reunidos no livro "Kinderspiel, Glücksspiel, Kriegsspiel: Große Geschichte in kleinen Dingen 1900-1945” (em tradução livre, “Jogo infantil, jogo de sorte, jogo de guerra, Grande História em pequenas coisas 19001945"), lançado em novembro de 2018 pela editora DTV em alemão e outras línguas. ${ }^{8}$

alegre e prazerosa que se desempenha ao concretizar as regras do jogo, ao mergulhar na ação lúdica (KISHIMOTO, 1996, p. 58-62).

${ }^{6}$ As metamorfoses na produção industrial dos brinquedos no final do século 19 e sua excepcional difusão na Alemanha levam Benjamin a constatar que, "considerando a história do brinquedo em sua totalidade, o formato parece ter uma importância muito maior do que se poderia supor inicialmente" (BENJAMIN, 2002, p. 89-94).

${ }^{7}$ BENJAMIN, 2002, p. 102.

${ }^{8}$ Uma amostra de leitura está disponível em: https://www.dtv.de/buch/andre-postertkinderspiel-gluecksspiel-kriegsspiel-28980. Acesso em: 28 set. 2020. 
Ao apresentar sua investigação delimitada na primeira metade do século 20, Postert descreve práticas e objetos muitas vezes macabros que foram extremamente populares em sua época: de bonecas e bonecos em uniformes militares a carrinhos e miniaturas de aviões, tanques e submarinos, réplicas de armamentos, jogos de tabuleiro, cartas de baralhos, cartelas de sorteios, dados, livros infantis ilustrados e fichas impressas, brinquedos com algum teor erótico, variações do xadrez tradicional e uma imensa diversidade de peças para montar. Os itens do inventário que Postert organizou, muitos deles incluindo reproduções fotográficas, surpreendem porque comprovam os indicativos explícitos de uma profunda e intensa propaganda para disseminar a ideologia bélica, violenta e antissemita. Como agravante, no perfil da grande maioria dos brinquedos e dos jogos com estratégias de batalha militar, na época das duas guerras mundiais, todos com muitas estampas de armas, suásticas, escudos e outros símbolos nazistas, os apelos para crianças e adultos eram sempre anunciados em destaque como "material educativo".

Na apresentação a seu inventário, André Postert destaca que jogos e brinquedos são reveladores sobre o comportamento de uma sociedade: eles representam o "zeitgest", o "espírito da época" ou o "sinal dos tempos". Segundo Postert, jogos, brinquedos e brincadeiras podem ser indicadores valiosos para fornecer instrumentos de crítica social sobre o passado observado no tempo presente porque retratam a história em todos os seus aspectos, incluindo aquelas questões que em sua época não foram compreendidas - ou porque estiveram mesmo ignoradas ou porque foram intencionalmente mascaradas com sérias intenções ideológicas. Nos arquivos do inventário sobre brinquedos surgem tanto aspectos referentes a questões de tecnologia e economia como as implicações sobre política, educação, comportamento, racismo, preconceito, fanatismo, religião, injustiça, crimes e guerras. "Alguns jogos e brinquedos são apenas uma moda passageira", aponta Postert, "enquanto outros experimentam um renascimento inesperado depois de décadas. Acredito que isso acontece porque jogos e brinquedos não apenas escrevem a história, mas também refletem a história". ${ }^{9}$

De acordo com o que Postert descreve e enumera em seu inventário, não só a partir da chegada de Adolf Hitler ao poder e à ditadura nazista na Alemanha, que abrange o período de 1933 até 1945, com o fim da Segunda Guerra, mas também desde os primeiros anos do século 20, jogos e brinquedos com orientação bélica, racista e antissemita ocupavam o mercado e as linhas de produção da poderosa indústria alemã, coincidindo com o predomínio dos brinquedos alemães no mercado mundial. $\mathrm{O}$ auge para tal indústria antecede a Segunda Guerra e termina por alcançar os índices recordes de maior produção global para a Alemanha nas décadas de 1920 e 1930. Sob

\footnotetext{
${ }^{9}$ POSTERT, 2018, p. 14.
} 
o controle de Hitler e do Partido Nazista, ${ }^{10}$ a Alemanha foi transformada em um estado totalitário fascista em que a vontade autoritária do Führer (o líder) estava acima das leis e controlava todos os aspectos da vida dos cidadãos. Na Alemanha Nazista, também chamada de Terceiro Reich, a indústria de brinquedos foi transformada em mais uma engrenagem da maior importância em sua gigantesca máquina de propaganda e controle social.

Enquanto os grandes fabricantes de brinquedos abraçavam as bandeiras do Terceiro Reich, em suas causas bélicas e racistas de perseguição e assassinato de judeus e outros grupos considerados indesejáveis, Joseph Goebbels, o todo poderoso ministro da Propaganda, atuava para lançar mão de todos os recursos para controle da opinião pública, censurando e também assassinando qualquer oposição na cena política, nas escolas e na cultura em geral, promovendo e financiando determinadas formas de expressão artística favoráveis aos planos nazistas e fascistas e proibindo qualquer questionamento ou resistência. Postert destaca que a indústria de brinquedos aceitou as formas de controle sem resistência e que o próprio Hitler, assim como Goebbels, ia publicamente a mercados, a empresas e a grandes lojas de departamentos no Natal e em datas cívicas para promover, em ações de publicidade e propaganda, certos jogos e brinquedos, distribuindo presentes diante da imprensa e das grandes plateias em situações planejadas nos mínimos detalhes. A mensagem era direta: "nós amamos as crianças e as crianças nos amam". ${ }^{11}$

Entre as grandes empresas que comandavam a produção industrial, listadas no inventário de Postert, há muitos casos que impressionam pelo conteúdo bélico e racista dos jogos e brinquedos, de propaganda do estado totalitário, e pelos altos volumes de vendas que tais itens alcançaram. Entre eles está o marco representado pela empresa Käthe Kruse, que adotou uniformes militares nazistas ou da Juventude Hitlerista para toda a sua extensa linha de bonecas e bonecos, ou o macabro "Juden raus!" (Fora judeus!), lançado em 1936 pela Günther \& Co. com o rótulo de "um jogo para toda a família". Na estratégia de extrema violência do "Juden raus!", jogadores assumem nas peças do tabuleiro o papel de policiais e, ao ritmo de fichas sucessivas e lances de dados, podem invadir propriedades, confiscar bens, prender famílias inteiras de judeus e fazer deportação de sequestrados para os campos de concentração. $\mathrm{O}$ vencedor era o jogador que conseguisse "recolher" seis judeus antes dos outros.

10 O Partido Nacional-Socialista dos Trabalhadores Alemães (Nationalsozialistische Deutsche Arbeiterpartei, abreviado como NSDAP), ativo entre 1920 e 1945, teve Adolf Hitler como líder desde 1921. O termo “Nazi" decorre de Nationalsozialist.

${ }^{11}$ POSTERT, 2018, p. 219. 


\section{Arquivo Maaravi}

A iniciação macabra aos rituais, à ideologia e às instituições do Terceiro Reich prossegue em muitos outros jogos e brinquedos investigados no livro de Postert. Havia também uma variedade de coleções de papéis de cartas, cartilhas didáticas e baralhos completos com retratos imponentes dos principais chefes do regime nazista, de Hitler a Goebbels, Göring, Himmler e outros comandantes militares, além de miniaturas de veículos reconstruídos em detalhes com bonecos representando personagens em seus uniformes militares oficiais. Hitler, com seu motorista e sua limusine preta, figuravam como recordistas de vendas.

Outro campeão de vendas "para toda a família" foi o jogo "A Corrida da Vitória da Suástica" (Der siegeslauf des hakenkreuzes), uma peça de propaganda explícita lançada quando Hitler tomou o poder em 1933. No jogo, as peças com suásticas eram movidas pelos jogadores de um campo a outro do tabuleiro, cada campo indicando momentos históricos do partido nazista desde sua fundação. O jogador que, depois de vários lances, pudesse ultrapassar os obstáculos dos opositores para chegar ao campo final, indicando 1934, vencia a batalha e destruía a democracia alemã.

O extenso acervo de jogos de tabuleiro e de brinquedos reunidos por Postert também representa um arsenal de doutrinação e de destruição, já que, na prática dos jogos e brincadeiras, principalmente as crianças, mas também os jogadores de todas as idades, aprendiam, reforçavam e espalhavam a ideologia fascista do regime com requintes de propaganda racista, militar e política, incluindo a preparação social para a guerra e seus crimes em massa, seus genocídios. Entre os documentos que impressionam pelas formas explícitas de violência que propagam, Postert reproduz, no capítulo denominado "Das Spiel des Überlebens - Spiele und Spielzeug im Holocaust" (O jogo da sobrevivência - Jogos e brinquedos no Holocausto), trechos de um comunicado público de 1933 da Associação de Fabricantes Alemães de Estanho que é revelador pelos termos que comemora: "Acabou-se com a corrida pacifista estúpida das sociedades da paz e das ligas femininas contra todos os brinquedos militares". ${ }^{12}$

Macabro e fúnebre, o saldo criminoso e assustador gerenciado pelo genocídio nazista ocasionou um cenário traumático que levou, no pós-guerra, pensadores como Hannah Arendt a chamar atenção para o que seria a "banalidade do mal". Arendt, filósofa alemã de origem judaica, em 1941 conseguiu fugir do campo de concentração de Gurs, na França, e embarcar para os Estados Unidos, fugindo da perseguição do nazismo. Em 1961, mais de 15 anos depois do final da Segunda Guerra, ela é enviada pela revista "The New Yorker" para acompanhar o julgamento, em Israel, de Otto Adolf Eichmann, tenente-coronel da Alemanha Nazista, e um dos principais mentores do Holocausto, que havia sido finalmente localizado e preso em 1960 em Buenos Aires, Argentina. Eichmann foi levado para Jerusalém para ser julgado - o julgamento de maior

${ }^{12}$ POSTERT, 2018, p. 279-280. 
repercussão internacional depois do Tribunal de Nuremberg. Com base nos relatos jornalísticos, nas entrevistas e nos artigos que escreveu para a revista norte-americana, Arendt publicou em 1963 o livro Eichmann em Jerusalém, que tem por subtítulo "Um relato sobre a banalidade do mal". ${ }^{13}$

Considerando as estratégias nazistas que resultaram no assassinato em massa de mais de seis milhões de judeus e de outras etnias durante a Segunda Guerra, Arendt ressalta que o acusado, presente naquele julgamento, não apresentava características de um caráter distorcido ou doentio e que ele alegava ter feito o que fez porque acreditava ser aquele o seu dever, cumprindo ordens superiores sem questionar. ${ }^{14}$ Ao apresentar sua própria observação sobre o processo como pressuposto de argumentação, Arendt desenvolve reflexões sobre filosofia e conduta ética, sobre o "desenraizamento" da experiência humana em relação à realidade, a mesma realidade percebida por Eichmann como uma relação contraditória, quase lúdica, de amoralidade e subserviência às regras burocráticas, conforme expressam algumas de suas falas durante as sessões do julgamento:

${ }^{13}$ ARENDT, Hannah. Eichmann em Jerusalém. Um relato sobre a banalidade do mal. Trad. José Rubens Siqueira. São Paulo: Companhia das Letras, 2013.

${ }^{14}$ Conforme o relato de Hannah Arendt, a Corte Distrital de Jerusalém fundamentou o julgamento de Eichmann com base na "Lei de Punição dos Nazistas e Colaboradores de Nazistas", criada em 1950, que possibilitava a aplicação da pena de morte para aqueles que ao longo do regime nazista (1933-1945) cometeram crimes contra o povo judeu. Com base na lei israelense, Eichmann passou a responder pelas acusações listadas a seguir: "(1) Provocar o assassinato de milhões de judeus; (2) Levar milhões de judeus a condições que poderiam levar à destruição física; (3) Por causar sérios danos físicos e mentais aos judeus; (4) Determinar que fossem proibidos os nascimentos e interrompidas as gestações de mulheres judias no campo de concentração Theresienstadt; (5) "Resumia os itens 1 e 2", como: propiciar condições que visavam a morte de milhões de judeus por meio da fome, deportação, trabalhos forçados, condições sub-humanas, destruição física e psicológica, cárcere...; (6) Por perseguir judeus com base em motivos raciais, religiosos e políticos; (7) Pilhagem de propriedade: confiscar bens de judeus através de medidas que envolviam a extorsão, o roubo e a violência; (8) Era responsável por crimes de guerra; (9) Pela expulsão de centenas de milhares de poloneses de suas casas; (10) Responsável pela deportação de 1400 eslovenos da Iugoslávia; (11) Era responsável pela deportação de milhares e milhares de ciganos para o campo de concentração Auschwitz; (12) Era responsável pela deportação e morte de 93 crianças da aldeia de Lidice, uma aldeia tcheca. Os três últimos itens o acusavam de pertencer a três organizações consideradas criminosas pelo Tribunal de Nuremberg: SD, Gestapo e SS" (ARENDT, 2013, p. 266-269). 
“Com o assassinato dos judeus não tive nada a ver. Nunca matei um judeu, nem um não judeu - nunca matei nenhum ser humano. Nunca dei uma ordem para matar fosse um judeu fosse um não judeu; simplesmente não fiz isso", ou, conforme confirmaria depois: (...) não deixou nenhuma dúvida de que teria matado o próprio pai se houvesse recebido ordem nesse sentido. ${ }^{15}$

O relato de Hannah Arendt também indaga sobre como teria sido a formação de Eichmann (o genocida que era, ao mesmo tempo, um perfeito homem de família) e de outros soldados e funcionários que movimentaram a burocracia do nazismo - e questiona a expressão do livre-arbítrio, a capacidade autônoma de escolher e decidir em função da vontade própria, a incapacidade de reflexão e empatia. O relato problematiza as motivações de Eichmann, porque Arendt percebe o criminoso como um homem "assustadoramente normal" e tratá-lo como demônio teria sido até "reconfortante". ${ }^{16}$ Ao examinar de forma peculiar, no passo a passo do julgamento, as alegações sobre ausência de pensamento e sobre a impossibilidade de discernir entre o certo e o errado, Arendt descobre o que ela vai descrever como ameaça maior às sociedades democráticas na história contemporânea: a "banalidade do mal", o potencial para o Estado transformar o exercício da violência homicida em uma espécie de jogo em progresso, em mero cumprimento de metas e organogramas. Um mal que envolveu o extermínio de milhões de seres humanos foi cometido por um homem limitado intelectualmente e cegamente leal ao cumprimento das ordens que recebia, movido pela obsessão cega de ser um burocrata exemplar e receber ao final sua recompensa pela vitória:

Quanto mais se ouvia Eichmann, mais óbvio ficava que sua incapacidade de falar estava intimamente relacionada com sua incapacidade de pensar, ou seja, de pensar pelo ponto de vista dos outros. Não era possível nenhuma comunicação com ele, não porque mentia, mas porque se cercava do mais confiável de todos os guarda-costas contra as palavras e a presença de outros, e, portanto, contra a realidade enquanto tal. ${ }^{17}$

Todos os indivíduos, mesmo em tempos sombrios, como ressalta a análise de Arendt, são responsáveis pelos seus atos, e diante de uma situação em que se exige deliberação, agem segundo seus juízos muito pessoais e obedecendo a um código de conduta, de comportamento e de ética ao qual foram apresentados ou condicionados. Todos os indivíduos pensam: agem em conformidade consigo mesmo, seguindo uma necessidade natural da vida humana. Para a filósofa, obedecer sem questionar é coisa para criancinhas. Mas obedecer e não pensar foi o que Eichmann fez. Não só ele, mas todos os alemães que disseram sim à fala autoritária e genocida de Hitler. Se Eichmann

\footnotetext{
${ }^{15}$ ARENDT, 2013, p. 33.

${ }^{16}$ ARENDT, 2013, p. 299.

${ }^{17}$ ARENDT, 2013, p. 62.
} 


\section{Arquivo Maaravi}

tivesse pensado, não teria feito o que fez, não teria seguido de forma automática as normas do jogo criminoso da organização. O caso de Eichmann não era de maldade, nem de estupidez, mas de irreflexão, como aponta Rosângela Chaves em diálogo com Hannah Arendt.

O indivíduo na sociedade moderna de massas tende a se ver como um simples dente de engrenagem em alguma espécie de maquinaria - seja a de uma corporação burocrática, social, política ou profissional, seja a representada pelo próprio caos da vida urbana. Daí, de acordo com Arendt, o grande clamor de todas as vezes que alguém atribui uma culpa específica a alguém em particular, ao invés de imputar a responsabilidade a alguma tendência histórica ou a um movimento dialético ou procurar uma justificativa de natureza abstrata, como o Zeitgeist, até o complexo de Édipo. ${ }^{18}$

Envolvido em polêmicas e muitas controvérsias, o julgamento em Jerusalém, que terminou em 1962 com Eichmann condenado à morte por enforcamento, fornece argumentos importantes para que Arendt reconheça uma ameaça constante para todas as sociedades democráticas, abordando o problema por uma perspectiva política e não moral ou religiosa. Eichmann era um cumpridor de ordens no jogo nazista: não sujava suas mãos de sangue, pois era um homem de gabinete que cometia tão somente "massacres administrativos". ${ }^{19}$ Ele representava seu papel de burocrata que assinava documentos em sua escrivaninha, autorizava, batia carimbos, e ao fazê-lo milhões de seres humanos eram transportados sob seu comando aos campos de concentração e de extermínio em lugares ocupados e administrados por nazistas após a tomada do poder em 1933.

Uma grande lei, acima de todas as regras e ritmos particulares, rege a totalidade do mundo dos jogos: a lei da repetição - alertava Benjamin, ${ }^{20}$ na esperança de encontrar nos artistas e nas crianças formas inspiradoras de entender o mundo e impedir a barbárie. Em 1933, quando Hitler chega ao poder, Arendt é impedida de seguir carreira de docência nas universidades por ser judia e deixa a Alemanha. Em Paris, torna-se amiga de Benjamin e trabalha, nos seis anos seguintes, com crianças judias expatriadas. Duas décadas depois, ao expor o que pensava sobre Eichmann, ela argumenta que quem propaga e perpetua o mal não precisa ser forçosamente um indivíduo sádico, genocida, monstruoso ou perverso - não é apenas isso que distingue a barbárie ou a prática do mal.

18 CHAVES, Rosângela. A capacidade de julgar. Um diálogo com Hannah Arendt. Goiânia. Canone Editorial, 2009. p. 139.

${ }^{19}$ ARENDT, 2013, p. 317.

${ }^{20}$ BENJAMIN, 2002, p. 101. 


\section{Arquivo Maaravi}

O mal, como ressalta Hannah Arendt, é um fenômeno político e histórico porque se repete e se manifesta apenas onde encontra espaço institucional - e sempre como resultado de uma escolha política. Sua banalização corresponde ao vazio de pensamento que transforma a violência homicida em mero cumprimento de metas e de organogramas burocráticos, ocasionando um risco permanente de que possa haver "um Eichmann dentro de cada um de nós". ${ }^{21}$ A repetição é a essência do jogo: por isso é importante destacar o cuidado que se deve ter, seja nas pequenas coisas da vida cotidiana, seja nas escolhas políticas, uma vez que o perigo iminente da banalidade do mal sempre permanecerá à espreita para ressurgir, dissimulado, sorrateiro, e até mesmo os objetos e as práticas na aparência triviais e inofensivos para o senso comum, como os brinquedos e as brincadeiras, podem ser instrumentos para espalhar e multiplicar, de forma monstruosa e perversa, contaminações de ódio e violência.

\section{Referências}

ARENDT, Hannah. Eichmann em Jerusalém. Um relato sobre a banalidade do mal. Tradução de José Rubens Siqueira. São Paulo: Companhia das Letras, 2013.

ARENDT, Hannah. Origens do totalitarismo. Tradução de Roberto Raposo. São Paulo: Companhia das Letras, 2009.

BENJAMIN, Walter. Obras escolhidas I - Magia e técnica, arte e política. Ensaios sobre literatura e história da cultura. Tradução de Sérgio Paulo Rouanet. São Paulo: Brasiliense, 1985.

BENJAMIN, Walter. Reflexões sobre a criança, o brinquedo e a educação. Tradução de Marcus Vinicius Mazzari. São Paulo, SP: Duas Cidades; Editora 34, 2002.

CHAVES, Rosângela. A capacidade de julgar. Um diálogo com Hannah Arendt. Goiânia: Cânone Editorial, 2009.

CORREIA, Adriano. Hannah Arendt. Rio de Janeiro: Jorge Zahar Editora, 2007.

HUIZINGA, Johan. Homo ludens: O jogo como elemento da cultura. Tradução de João Paulo Monteiro. São Paulo: Perspectiva, 1993.

KISHIMOTO, Tizuko Morchida (org.). Jogo, brinquedo, brincadeira e educação. São Paulo: Cortez, 1996.

MANSON, Michel. História do brinquedo e dos jogos. Brincar através dos tempos. Tradução de Carlos Correia Monteiro de Oliveira. Lisboa: Teorema, 2002.

POSTERT, André. Kinderspiel, Glücksspiel, Kriegsspiel: Große Geschichte in kleinen Dingen 1900-1945. Munich, Germany: DTV, Deutscher Taschenbuch Verlag, 2018.

${ }^{21}$ ARENDT, 2013, p. 309. 


\section{Arquivo Maaravi}

WAJSKOP, Gisela. Brincar na Educação Infantil. São Paulo: Cortez, 2012.

Recebido em: 23/02/2021.

Aprovado em: 23/03/2021. 